University of Nebraska - Lincoln

DigitalCommons@University of Nebraska - Lincoln

Faculty Publications, Department of Psychology

Psychology, Department of

$12-2009$

\title{
Assuming Elder Care Responsibility: Am I a Caregiver?
}

Lindsey E. Wylie

University of Nebraska-Lincoln, slwylie@unomaha.edu

Eve M. Brank

University of Nebraska-Lincoln, ebrank2@unl.edu

Follow this and additional works at: https://digitalcommons.unl.edu/psychfacpub

Part of the Elder Law Commons, and the Psychology Commons

Wylie, Lindsey E. and Brank, Eve M., "Assuming Elder Care Responsibility: Am I a Caregiver?" (2009). Faculty Publications, Department of Psychology. 980.

https://digitalcommons.unl.edu/psychfacpub/980

This Article is brought to you for free and open access by the Psychology, Department of at DigitalCommons@University of Nebraska - Lincoln. It has been accepted for inclusion in Faculty Publications, Department of Psychology by an authorized administrator of DigitalCommons@University of Nebraska - Lincoln. 
Published in Journal of Empirical Legal Studies 6:4 (December 2009), pp. 899-924; doi: 10.1111/j.17401461.2009.01164.x

Copyright (C) 2009 Cornell University Law School; published by Wiley. Used by permission.

First published December 15, 2009.

\title{
Assuming Elder Care Responsibility: Am I a Caregiver?
}

\author{
Lindsey E. Wylie and Eve M. Brank
}

Law-Psychology Program, University of Nebraska-Lincoln, Lincoln, Nebraska, USA

Corresponding author - Lindsey Wylie, PO Box 880308, University of Nebraska-Lincoln, Lincoln, NE 68588-0308, email lwylie@huskers.unl.edu

\begin{abstract}
Caregivers of the elderly face conflicting legal demands; they must make certain the elder's needs are being met while not forcing undesired care on an adult capable of informed decisions. This dichotomy may be a reason a large volume of reported elder abuse derives from unintentional neglect on behalf of informal familial caregivers. The current research examines this possibility with exploratory interviews and an experiment. The interviews between elders and their family (30 dyads) revealed that many did not intend for the living arrangements to become permanent, and the nonelders were largely unprepared for the magnitude of changes and responsibilities that would result. The elders often expressed a sense of loss for their former life and feeling supernumerary in the family. In the experiment, we examined whether a person recognizes when a caregiving relationship exists and the factors that contribute to notions of being a caregiver. Results suggest that potential caregivers (124 community members) focus on the relationship with the elder more than the elder's physical and financial needs, and generally have stronger feelings of moral responsibility rather than legal responsibility to provide care.
\end{abstract}

\section{Elder Autonomy and Paternalistic Caregiving}

Caregivers of the elderly face contradictory legal demands because paternalistic caregiving may conflict with an elder's right to autonomous decision making. This conflict is further complicated by three major factors. (1) We lack clear definitions of which elders require care and who is responsible for providing that care (Brank 2007). (2) If an active decision 
is made to enter into an informal caregiving relationship, it is often based on moral or emotional rationalizations, which research suggests will result in less optimal decisions (Baumeister et al. 2006). (3) A large number of reported elder injuries are caused by unintentional neglect by informal familial caregivers (Teaster et al. 2006). Therefore, in an effort to address the conflict between paternalistic caregiving and elder autonomy, the current research examines the legal definitions for caregivers, some of the decision-making strategies employed, and knowledge of being in a care relationship. Ultimately, the goal of this research is to highlight how the law, based on empirical research, can better address elder caregiving and reduce elder maltreatment.

Although extreme cases of abuse exist, many incidents of elder abuse and neglect are subtle, and the distinction between normal interpersonal stress and abuse is often difficult to differentiate (APA 2008). According to a recent national survey on reported abuse of adults over the age of 60, self-neglect was the most common form of abuse, with caregiver neglect as second (Teaster et al. 2006). Most commonly, abuse and neglect were related to changes in the living situations and relationships brought about because of the elder's increased dependency on others (APA 2008).

Many families will face the decision of how to provide care for an elderly or disabled loved one as the population continues to age (Heron et al. 2008). Although assisted-living facilities are sometimes an option, a number of people are choosing to take on the caregiving within the home. Unpaid family caregivers will likely continue to be the largest source of long-term care services in the United States, and estimates are expected to reach 37 million caregivers by 2050, an increase of 85 percent from 2000 (Health and Human Services 2003). This increase has been attributed to elder preference for remaining with family and family preference for avoiding nursing-home placement (Dellmann-Jenkins \& Brittain 2003; Kapp 1995).

\section{Legal and Social Definitions of Caregiving}

In the Florida case of Sieniarecki $v$. State of Florida (2000), Theresa Sieniarecki and her three siblings faced the decision of how to care for their mother, who had undergone two hip surgeries and was deteriorating mentally. When the family home where Theresa's mother lived was sold due to foreclosure, Theresa and her mother moved into an apartment together. Theresa testified that most of the caregiving responsibility fell on her, which included changing her mother's diapers, providing her with food, and encouraging her to go to the doctor (Sieniarecki v. Florida 2000). Theresa's mother died from malnutrition and infection complications shortly after they began living together. In the elder neglect case brought by the state, Theresa argued that she was unaware she had "assumed responsibility" (meaning she was not aware she had taken over the duties and responsibilities) leading to a legal obligation to care for her mother. Furthermore, Theresa asserted that she did not want to interfere with her mother's rights to refuse medical treatment because she was unaware that her mother was incapacitated and that she was considered a "disabled adult" (Fla. Stat. § 825.101; see Sieniarecki v. Florida 2000:75).

The Florida Supreme Court disagreed with Theresa and opined that she had "assumed responsibility" for her mother by moving in with her and taking on the responsibility to 
care for her mother. The court noted that anyone in Theresa's situation would have known that he or she was a caregiver and needed to provide appropriate care-by providing the care himself or herself or seeking assistance from others. Although not specifically stated in the opinion, the court's decision implies that Theresa should have compelled her mother to eat and seek medical care. Theresa Sieniarecki was convicted of elder neglect and sentenced to 22 months in prison because she had not appropriately carried out her caregiving role. Obviously, ignorance of the law is not a defense, but Theresa's claim was that her mother was an autonomous adult and died as a result of self-neglect. The sections that follow will examine legal definitions of caregiving as well as definitions of those who require care.

\section{A. Filial Responsibility-A Precursor to Caregiving Laws}

Filial responsibility is a social norm that describes the generalized expectation that adult children should help an aging parent in times of need (Cicirelli 1990; Gans \& Silverstein 2006). Although filial responsibility is often thought of as a social value, there is a legal history of mandating adult children and relatives to support an aging family member (Edelstone 2002; Pakula 2005a; Moskowitz 2001). Adapted from the Elizabethan Poor Relief Act of 1601, colonial American law required adult children to care for their aging parents (Rosenbaum 1967). Currently, 30 states still have filial responsibility laws with varying degrees of criminal penalties, ranging from monetary fines to incarceration (Moskowitz 2001; Pakula 2005b), even though the laws are arguably outdated and unenforceable (Edelstone 2002; Pakula 2005a; Moskowitz 2001).

Many states repealed their filial responsibility laws in 1964 when Medicaid and Medicare were established for the aging population's medical and financial needs (Pakula $2005 \mathrm{~b}$ ). For those states that still have these laws, some require adult children over the age of 18 to support an indigent parent financially (see New Hampshire RSA 167:3; South Dakota Codified Laws $\S 25-7-27)$. Other states have similar statutes requiring adult children to provide financial support, but they contain a provision termed "reciprocal contract," in which an adult child is obligated to support the elder only if the adult child "during his minority [was] reasonably supported by such parent" (see Massachusetts, ALM GL ch. $273, \S 20$ ). In addition, other states have financial conditions in which caregivers can seek reimbursement from siblings and the government can seek compensation if government assistance was provided for the elder (see Connecticut Gen. Stat. § 46b-215).

\section{B. Elder Caregiving Laws}

In the absence of filial responsibility laws and their enforcement, many adult children and others still take on elder caregiving responsibilities. States define elder caregivers in different ways, but it is often done within the context of abuse and neglect statutes. In Illinois, a caregiver is defined both in the Aging Chapter ( $\$ 320$ ILCS 20/2) and the Criminal Code (§ 720 I.L.C.S. 5/12-21). In the Aging Chapter, a caregiver is simply described as a "person who either as a result of a family relationship, voluntarily, or in exchange for compensation has assumed responsibility for all or a portion of the care of an eligible adult who needs assistance with activities of daily living." The Criminal Code provides more detail by defining a caregiver as a "person who has a duty to provide for an elderly person or person 
with a disability's health and personal care, at such person's place of residence, including but not limited to, food and nutrition, shelter, hygiene, prescribed medication and medical care and treatment." It continues by defining who could fit that role as a parent, spouse, adult child, or other relative who resides with the person and knows or reasonably should know of the elder's needs; as a person who is employed by the elderly person to reside with or regularly visit the elder; or as a person who has been appointed to provide such care.

In Georgia, for the purposes of receiving support from the state, a caregiver is defined as the person who has "assumed the primary responsibility for the provision of care needed to maintain the physical or mental health of a functionally dependent older adult ... who lives in the same residence ... and who does not receive financial compensation for the care provided" (O.C.G.A. § 49-6-72). Georgia's use of the word "assumed" is common in other states also (e.g., Alaska Stat. § 47.24.900; Fla. Stat. § 825.101).

A caregiver can be any number of people, including, but not limited to, "relatives, household members, guardians, neighbors, and employees and volunteers of facilities" (Fla. Stat. $\S 415.102$; see also 720 I.L.C.S. 5/12-21; Louisiana R.S. 14:93.3). A caregiver relationship may be either voluntary or legally appointed (e.g., Burns Indiana Code Ann. § 35-46-1; La. R.S. 14:93.3; RSA 631:8), and either temporary or permanent (e.g., Fla. Stat. § 415.102; La. R.S. 14:93.3; South Carolina Code Ann. § 43-35-10).

Once someone has assumed the responsibility to provide care, the caregiver must also ensure the elder receives adequate care, and it is illegal, whether through commission or omission, to withhold essential needs (Kapp 2004). Some statutes even go as far as requiring caregivers to "carry out the treatment plan prescribed by a health care professional" (e.g., 31 Delaware C. § 3902) (see Bonnie \&Wallace 2003). Although state statutes take different approaches in addressing caregiving and appropriate levels of care once a caregiving relationship is established, most seem to imply a paternalistic approach to caregiving in that caregivers are ultimately responsible for an elder's well-being. To complicate matters further, many states also bar the state or a family member from interfering with medical treatment decisions by consenting adults, even in matters of life and death (Glick 2005). This means that because caregivers are now handling far more medical responsibilities than ever before (O'Mara 2005), they must ensure the elder's medical needs are being met, while maintaining an elder's autonomy by not forcefully requiring medical compliance on an adult capable of making informed medical decisions.

\section{Empirical Research on Filial Responsibility and Elder Caregiving}

To date, research that has investigated various issues of filial responsibility mostly derives from social gerontology and family studies. These studies have examined individual differences of filial responsibility and whether filial responsibility changes within individuals according to the circumstances. Studies have found that expectations that adult children should be responsible for their aging parents do vary across individuals. More specifically, filial norms are stronger among women and become weaker as individuals reach midlife (Gans \& Silverstein 2006; Ohuche \& Littrell 1989). One study compared a group of young adults who were elder caregivers to young adults who were not elder caregivers. Attitudes of filial responsibility were similarly positive toward helping aging relatives (Dellmann- 
Jenkins \& Brittain 2003). Thus, current elder caregiving status, at least among young adults, does not appear to affect attitudes of filial responsibility norms.

Much of the social science research and legal analyses concerning elder caregiving has been limited to caregiver burden and motivation to care for an elder. Research has indicated that many caregivers experience severe mental distress as a result of multiple responsibilities (Butler et al. 2005) because most caregivers are family members who must balance several roles in addition to caring for the elder, including caring for dependent children of their own and maintaining employment (Anetzberger 2000; Brody 1990). The resulting caregiver burden is thought to be a major antecedent for elder abuse and neglect (Anetzberger 2000), and is especially important to understand because most abuse and neglect occurs by family members in the home (APA 2008; Jayawardena \& Liao 2006).

Despite these known caregiver burdens, most people express strong support toward caring for an elderly relative for reasons of respect for the elder (Dellmann-Jenkins \& Brittain 2003; Ohuche \& Littrell 1989) or felt moral obligations (Bracci 2000; Wolfson et al. 1993). To illustrate, Wolfson and colleagues (1993) explored both moral responsibility of caregiving and the caregiver's awareness of legal obligations for caregiving. In that study, caregivers were questioned on felt responsibilities and resources available for providing the elder with care. Most participants felt a strong moral obligation to provide care; however, when participants were asked of their awareness of any legal obligations for families to provide for the elderly, only 11.8 percent knew of such legal responsibilities.

In addition to research surrounding caregivers, research has also examined expectations elders have for family members to provide them with care, which may also pose unique legal implications for elder caregiving policy. Using vignettes that manipulated characteristics of adult children, Van der Pas and colleagues (2005) demonstrated that aging adults aged 61 to 92 were more likely to expect care from adult children who are unemployed. This may present a problem because even though an unemployed adult child may have fewer daily obligations, thus allowing more time to provide care, an unemployed adult child may not be able to provide adequate financial support. In fact, the financial burden of the elder on the caregiver has been identified as another antecedent for elder abuse (APA 2008). Lee et al. (1994) found that aging adults are more likely to expect care from family members when the elder lives in a remote rural area, yet isolation (as is the case in rural areas) has also been identified as an antecedent for abuse and neglect (Glick 2005; Kohn 2003).

Public perceptions and the legal understanding of potential caregivers is an area of research that is still underinvestigated. Scholars have acknowledged the need for research into elder laws; however, most social science research has limited its scope to examination of felt moral obligation experienced by adult children or filial responsibility, and most legal analyses have focused on filial responsibility laws. Another problem is that most research and state laws assume individuals are aware of their caregiving role even though cases, such as Sieniarecki, have demonstrated that caregiver laws may not be as explicit as these studies and statutes presume. Therefore, several questions surrounding caregiving relationships and caregiver laws still remain unanswered: Do individuals know when they are considered a caregiver for the purposes of the law? Are caregivers aware of potential legal consequences for what they believed was a moral decision to take care of an elder? Do 
variations within the caregiving situation affect whether or not people view themselves as a caregiver? Are current caregivers prepared for providing an elder with care in terms of requirements outlined in statutory definitions?

\section{Decision Making and Elder Autonomy}

To better understand these psycholegal issues surrounding caregiving relationships, it is important to understand psychological processes that may contribute to decision-making in elder care, specifically models that may explain whether a person would consider himself or herself a caregiver. One such area is elder autonomy, which could influence whether a potential caregiver believes an elder requires care, or whether a person wants to "interfere" with an elder's sense of independence.

Often cited in both legal and social science literature on elder care are notions of elder autonomy (Barber 2008; Cicirelli 1990, 2003; Glick 2005). An elder's autonomy-or level of independence - is often a defining factor for determining whether someone is delineated a caregiver. Albert and colleagues (1996) investigated family caregivers' varying thresholds for deciding when they became "caregivers" and were no longer just "occasional helpers." By retrospectively asking current caregivers when their caregiving duties began, the findings show that self-perceived start of caregiving differed greatly across caregivers, and that level of elder autonomy was a defining factor for commencement of caregiving across all caregivers. In addition, Cicirelli (2000) describes a trajectory of caregiving roles in terms of stages of development. After studying caregiving dyads, caregivers appeared to "move to the next stage" and view themselves as caregivers according to the elder's level of function.

In addition to defining the caregiving relationship, issues of elder autonomy may also arise during caregiving, which may further add to the legal debate. Once in a caregiving relationship, researchers have suggested that autonomy is an important aspect of aging because it promotes well-being (Reis et al. 2000) and is an indicator of successful aging (Ford et al. 2000). Similarly, most caregivers view upholding autonomy as important within caregiving relationships. For example, Horowitz et al. (1991) found that family caregivers were more sensitive to elder autonomy than the elders were and that the majority (67 percent) of caregivers encouraged the elder to do things on his or her own, so as to not interfere with the elder's sense of independence. However, as exemplified by Sieniarecki, honoring an elder's autonomy, such as not forcing medical compliance or proper nutrition, may not always be in the elder's best interest. Again, though, the challenge arises when caregivers are presented with the dilemma of circumnavigating both legal requirements of providing care and legal requirements respecting self-determination.

\section{Current Studies}

The current research involved two separate studies. The first study is an exploratory study that employed interviews of elders and their family-member caregivers. Elders and nonelder family members answered questions about how they decided to live together, how prepared they were for the situation, and how their daily life was managed. The second study is a vignette-based experiment that manipulated the type of relationship between a 
described elder and caregiver and also manipulated the type of help that was needed by the elder. Participants answered questions concerning caregiving responsibilities and notions of caregiving.

\section{A. Study 1-Exploratory Interviews with Elders and Their Family Members}

\section{Method}

Our first study employs in-depth interviews with elders and their family members. Recruitment of participants was done mostly through elder care service facilities and physicians' offices. To qualify for the study, the elder must have been 65 years or older and living with a family member (other than a spouse) for at least two months but no longer than 10 years. The nonelders were purposely not referred to as "caregivers" in recruitment or during the interviews in case any of them did not view themselves as an official caregiver. Each participant pair (elder and family member) who completed the interview was paid $\$ 20$ per person. The interviews generally took about one hour each to complete (elder interview: $M=40$ minutes, $S D=16$ minutes; nonelder interview: $M=66$ minutes, $S D=18$ minutes) and were conducted simultaneously by two separate interviewers in separate areas of the homes where the participants lived.

a. Participants. The sample included 60 people residing in North Central Florida: 30 elders ( $M=80.65$ years, $S D=9.32,23$ females and 7 males) and 30 nonelder family caregivers $(M=52.31, S D=11.54,28$ females and 2 males). Four participants were Hispanic, 16 were black, and 40 were white. The living situations were as follows: 15 mothers moved in with their daughters, four daughters moved in with their mothers, three daughters moved in with their fathers, two fathers moved in with their daughters, one daughter and mother moved in together in a new home, one granddaughter moved in with her grandmother, one daughter moved in with her mother and father, one father moved in with his son, one brother moved in with his sister, and one mother moved in with her son.

b. Interview Questions-Elder Interview. Elders were asked 18 questions from the Life Satisfaction Index (Adams 1969; Neugarten et al. 1961) that has been used extensively in aging populations (see Wallace \& Wheeler 2002). The scale has questions such as "I am just as happy as when I was younger" and "These are the best years of my life." Response options are agree, disagree, or I don't know. Seven items are reverse coded so that higher scale summation scores reflect greater life satisfaction (possible score range of 0 to $18, \alpha=0.66$ ).

Open-ended questions were included that assessed the elder's experience with medical professionals and daily living. Elders were also asked open-ended questions about the decision to move in with their family members, how the decision was made, and what factors they saw as contributing to the decision (see Appendix A for example items). The elders' feelings about the decision to move in with a family member were assessed with two different scales. The first was an 11-item procedural justice questionnaire modified from the Family Justice Inventory by Fondacaro et al. (2002) that asked elders how they were treated during the decision-making process. For instance, one question asked: "Your family member(s) considered what you said when making their decision." Response options were on 
a five-point scale ranging from strongly disagree to strongly agree. Scores were averaged across the 11 questions for a possible scale score of 0 to 4 , with higher scores indicating that the elder felt he or she had been treated in a more procedurally fair way $(\alpha=0.74)$. The second measure of the decision-making process employed a vignette modified from a study by Wolfson and colleagues (1993). The vignette described an 81-year-old woman named Ann who needed physical help with daily living. After the interviewer read the vignette, the interviewer asked whether the family should move in with Ann, Ann move in with the family, or the family and Ann move in together in a new home. The interviewer adjusted these response options to match the living situation of the family being interviewed. The elder then provided an agreement rating (from 0 to 4 , with 0 being strongly disagree and 4 being strongly agree). The interviewers also asked what advice they would give to Ann and her family. The intent of including this vignette was to increase objectivity and reduce response bias (Wolfson et al. 1993). We wanted to provide the elders with an opportunity to talk about their own living condition but "removed" from their own situation.

c. Interview Questions-Nonelder Interview. The nonelders answered a series of questions that provided information about the level of care they were providing for the elder. We used the Katz Index of Independence in Activities of Daily Living (Katz 1983) and a medical conditions checklist developed for the current study. They were also asked about caregiving burdens and how bothered they were by different common caregiving experiences (based loosely on the Caregiving Hassles Scale) (Kinney \& Stephens 1989). Responses were on a five-point scale to the question, "How much does this bother you?" for six different areas of caregiving (e.g., bathing and toileting). Response options ranged from 0 (not at all) to 4 (very much). Mean scores were calculated, with higher scores indicating the caregiver was more bothered $(\alpha=0.77)$.

An additional 38 questions from the Caregiver Burden Scale (Stull et al. 1994) and modified Caregiver Hassles Scale (Kinney \& Stephens 1989) were included. The scale included questions such as "I wish I could escape from this situation" and "I resent him/her." The respondents were told to indicate how descriptive the statements were about them, with response options ranging from 0 (not at all descriptive) to 4 (very descriptive). One overall burden score was computed by averaging the responses across all 38 questions ( $\alpha=0.94$ ). Higher scores indicated greater caregiving burden. The interviewers provided the nonelders with a paper and pencil version of this set of questions because of the sensitive nature and to encourage more truthful responses than what might have been obtained if they would have been asked as part of the oral interview.

Nonelders were also asked open-ended questions about the decision to live with the elder, how the decision was made, and what factors they saw as contributing to the decision. They were asked to describe any preparations that were made to the home if the elder was the one moving and if there had been any financial strain because of the living situation. Additional information about interactions with medical professionals, daily living, and legal concerns were also discussed (see Appendix A for example items). The nonelders also answered the same questions related to the vignette described above in the elder question section. 


\section{Results}

Because interviews were intended to be exploratory, results will be descriptive and discussed in terms of trends. We will first address the elder responses and then the nonelder responses. Last, we will discuss those questions that both the elder and nonelder answered to glean insights into their different viewpoints on the same issues.

a. Elder Responses. Two elders were not able to provide valid consent to participate in the study. The remaining results are based on the responses from the other 28 elders. Elders in the current sample reported, on average, a moderate level of life satisfaction $(M=11.74$, $S D=3.02$, possible range from 0 to 18 ). They also had fairly high procedural justice scores $(M=3.11, S D=0.52$, possible range from 0 to 4$)$, indicating that for this sample, the elders felt that they were part of the decision-making process and were treated fairly by their family in the decision to move in together.

When asked about what they did in a normal day, what kinds of activities the elders enjoyed, and how often they engage in the activities they enjoyed, 46 percent said that they could not do one or more of the activities they once enjoyed. Almost 40 percent said that watching television was an activity they enjoyed. Fourteen percent said they did "nothing" in a day. Half the elders said that they left the home two or fewer times per week and 32 percent said that they left their home every day. The elders were asked how often they saw their friends, and their responses basically fell into three different categories: (1) 39 percent said they saw their friends every day, (2) 29 percent said they saw their friends two or less times per week, and (3) 32 percent said that they did not have any friends or did not see their friends at all (three elders specifically mentioned that because they had moved to a new city they did not know anyone and had not made new friends).

b. Nonelder Responses. Based on the nonelders' responses to the Katz Index of Independence in Activities of Daily Living, our current sample includes eight elders who are still completely independent (no help needed with bathing, dressing, toileting, transferring, continence, or feeding) and one elder who was completely dependent on his caregivers for these daily living tasks. The rest of the sample ( 21 elders) needed varying levels of assistance. The nonelders reported being bothered the most by needing to help their elder family member with transferring (e.g., moving from bed to chair), but even their mean scores for this item $(M=1.83, S D=1.83)$ were quite low (scale ranged from 0 to 4 , with 4 being higher bother). Overall, the nonelders reported moderately low levels of caregiver burden $(M=1.24, S D=0.73$, possible range from 0 to 4 , with higher scores indicating more burden).

Only three of the nonelders in our sample did not view themselves as the primary caregiver. One said she was not because she shared the responsibility with her sister; however, the sister did not live in the same house. One nonelder indicated that the elder did not need a caregiver and another respondent said his spouse was the primary caregiver. Only three of the nonelders reported that they received financial help from other members of their family for the cost of caregiving. Fourteen of the nonelders reported that they either had to quit their jobs or significantly reduce their work schedules when the living arrangement with the elder began. 
All the nonelders reported that the move has affected other family members who live in the same home. For instance, one reported a great deal of strain on a relationship between herself and her fiancé because of the additional person moving into their home. Another nonelder reported that her children were embarrassed by their grandmother when friends visited. For the 25 nonelders who had the elder move in with them, 12 indicated that they made changes to their homes, such as adding grab bars in the bathrooms, ramps for wheelchairs, and removing loose rugs from the floors. The one family who moved into a new home together had the home custom built to be handicapped accessible. The nonelders were also asked about how compliant the elders were in terms of their medical care. Almost all the nonelders (93 percent) said that they attend doctor visits with the elder, and 70 percent said that they handle the elder's prescription medications. One-third of the nonelders said that the elders "refused" or were "unwilling" to take prescribed medications or follow other medical advice.

Only one of the nonelders indicated that he or she thought there were legal obligations of families to care for elderly parents. Approximately half (53 percent) said that they knew there were laws that forbid physical abuse. None of our nonelder participants had been made a formal guardian of the elder. Twenty-five reported being the elder's healthcare proxy, but it was unclear whether there was actual understanding of what that meant.

c. Complementary Responses. Both the elder and the nonelder were asked a number of the same questions to compare their perspectives. When both were asked about the reasons for moving in together, health deterioration or a health event (e.g., a fall or a heart attack) was the most cited reason (46 percent). Forty-three percent of the nonelders said that they did not discuss with anyone the decision to move in together. Forty-seven percent talked about the decision with at least one family member, and 10 percent spoke with a doctor. Somewhat similarly, 44 percent of the elders said they did not discuss with anyone the decision to move in together. Forty-eight percent talked about the decision with at least one family member, 4 percent talked with someone from church, and another 4 percent talked with doctors. Various reasons were cited for why this particular nonelder was the one caring for the elder. For instance, one reason cited for being best suited was that the nonelder had just gone through a divorce and did not have a permanent home. Elders and nonelders were both asked whether the living situation was intended to be long term. Twothirds of the nonelders reported that they intended for the living arrangement to be long term, and approximately 50 percent of the elders said they intended it to be long term. Both participants were asked about other potential options and why assisted-living or nursinghome facilities were not chosen. More of the nonelders (37 percent) than the elders (20 percent) indicated that they considered an assisted-living or nursing-home facility (see Table 1). One nonelder stated that when she was younger she had promised her mother she would not put her in a nursing home. This same nonelder had quit her job in order to care for her mother. 
Table 1. Complementary Responses: Percentage of Elders and Nonelders Describing the Decision to Move in Together

\begin{tabular}{lcc}
\hline Question & Nonelder Responses & Elder Responses \\
\hline Who did you talk to about moving in together? & & \\
No discussion with anyone & $43 \%$ & $44 \%$ \\
At least one family member & $47 \%$ & $48 \%$ \\
Doctor & $10 \%$ & $4 \%$ \\
Church & $0 \%$ & $4 \%$ \\
The living arrangement intended to be long term. & $66 \%$ & $50 \%$ \\
Considered an assisted-living/nursing-home facility. & $37 \%$ & $20 \%$ \\
\hline
\end{tabular}

Both the elders and nonelders were asked about the vignette describing an elderly woman, Ann, and whether she should move in with her family, her family move in with her, or they move in together (only the option that reflected the participant's living situation was presented). A majority of the elders in our sample (83 percent) agreed or strongly agreed that the family should make this move. Similarly, a majority of the nonelders in our sample (86 percent) agreed or strongly agreed that the family should make the move.

After providing their agreement ratings for the vignettes, we asked the nonelders and elders to provide advice for both Ann's family and Ann. The elders' advice for the fictional family generally concerned the family being compassionate, loving, and patient toward Ann. The most common advice (43 percent) provided related to the family understanding the elder's perspective and feelings. The next most common response (17 percent) from the elders related to the family encouraging independence and activities for Ann. One elder suggested that the family think about what kind of activities Ann would want to do and to try to include Ann in their lives. Similarly, another elder suggested that the family pay attention to Ann "every once in a while." One elder suggested that the family let Ann go to a nursing home or make some arrangements for someone to live with Ann in her own home. The nonelders' most common responses for the fictional family were to try to understand Ann's perspective (40 percent) and to explore alternatives for assistance (33 percent). One nonelder said that the family should be prepared for "things not to be like they used to be." Another recommended that the family try to encourage Ann to maintain friendships and activities outside the family.

In providing advice for Ann, the elders suggested that she will need to learn not to dwell on the past and to conform to her new life. The most common advice ( 33 percent) related to Ann accepting her situation and complying with the requests of the family. The next most common piece of advice was for Ann to explore other alternatives before moving (20 percent). One elder said, "Ann should accept that she may not be a part of their happy life." The nonelders' advice for Ann focused on Ann understanding the caregiver's perspective and feelings (67 percent). More than one-fourth (27 percent) gave advice related to Ann's compliance: compliance with physicians' orders and compliance with the rules of the new living arrangement. One nonelder said that Ann needed to appreciate what the family has done for her because they will have "completely rearranged their lives for her." 


\section{Study 1 Discussion}

Study 1 represents an attempt at learning from both elders and their nonelder family members about the decision to live together. Even with the small and preliminary sample, some patterns emerge. The interviews paid close attention to the decision-making process and any unintended and unexpected consequences of living together because some state statutes have defined a caregiver as one who has "assumed responsibility" for the care of an elderly person (e.g., Alaska Stat. § 47.24.900; Fla. Stat. § 825.01; O.C.G.A. § 49-6-72) either explicitly or implicitly (Nebraska 28-353). Additionally, state case law suggests that some caregivers may claim that they do not know when they take on this role (Sieniarecki v. State 2000).

The results from the preliminary interviews suggest that families are often entering into caregiving situations without intending for them to be long-term care. Consistent with earlier research (van der Pas et al. 2005), family members who were unemployed or without children were often relied on for caregiving. In other words, the family member with the least stable career/job and home life (e.g., a daughter who had recently been divorced) was the one who was said to be the "natural" choice for the caregiving role. Of course, the problems with this kind of tactic are clear: caregiver emotional, physical, and financial burden are likely to be exacerbated when the caregiver is already struggling with self-management issues.

It was apparent that the nonelders were largely unprepared for the magnitude of the care they would be providing. Several were forced to quit their jobs or modify their work schedules to accommodate providing care. Despite this, the nonelders reported relatively low caregiver burden levels. Even though the interviewers had the nonelders answer the caregiver burden questions on their own and not as part of the oral interview, their answers might reflect a social desirability effect of not wanting to indicate, for instance, that they were frustrated or embarrassed by the elder. Making this portion of the interview anonymous (e.g., allowing the participant to seal responses in an envelope) might have been helpful.

Most participants had very little legal knowledge of caregiving responsibilities and none had been made a formal legal guardian of the elder. This becomes important when combined with the nonelders' responses concerning the elders' health-care compliance. Some of the nonelders described the elders as noncompliant in taking care of their medical needs. Although some of the nonelders said that they helped remind the elder to take prescribed medications, it is clear that many of them still view it as the elder's responsibility and, similar to the findings by Horowitz et al. (1991), many caregivers may not want to impose on the elder's sense of independence. Some caregiving statutes elevate medical care to the same position as clothing, shelter, and supervision in the list of services the caregiver is to ensure the elder receives in order to not be neglectful (see Fla. Stat. § 825.102(3)(b)). Although it is premature to make any real conclusions from the current small sample, it is important to note that the caregivers seem to view health-care decisions as still within the purview of the elder's autonomous decision-making power. In other words, many of the caregivers gave the impression that it was the elder's decision whether to comply with a physician's orders even though the legal requirements are clear that if a person has 
assumed a caregiver role he or she is to ensure the elder is provided with medicine and medical services to maintain the "well-being" of the elderly person.

\section{B. Study 2-Experimental Study Examining Caregiving}

\section{Method}

a. Design. Study 2 employed a self-referencing vignette methodology $\left(\mathrm{O}^{\prime} \mathrm{Connor}\right.$ et al. 2004; Wiener \& Hurt 2000). All the scenarios described two individuals, an elder and a potential caregiver, and were based on what elderly people may experience as they age. Two variables were manipulated within each vignette. The first was based on the legal standard for caregiving and included the relationship of the elder to the potential caregiver (mother/father, spouse, aunt/uncle, client to a hired home assistant, and roommate). The second was based on the elder autonomy research and included the type and level of help needed by the elder person (financial management help, major financial help, some physical help, major physical help, and both financial and physical help). For each level of the independent variable to be crossed with each other, 25 total vignettes were created. Because these judgments are subjective to each individual, a between-subjects design, in which each person receives only one vignette, was not appropriate. Similarly, participants should only be exposed to each level of the independent variable once; therefore, each participant received only five of the 25 vignettes. For example, if a participant was assigned to the condition with financial management and mother, this participant would not receive any other vignettes with these two variables. The vignettes are described in more detail later.

b. Procedure. The current study used WEXTOR, a website managed by the University of Zurich, in order to construct a randomized web experiment study. This website constructed the html code for the web study, including a special code for randomization. When a participant logged on to the webpage hosting the study, the website assigned and determined which group of vignettes the participant would receive. Once the participant was assigned to a random group, the consent form was given and the five vignettes within that group were presented in random order. After the presentation of each vignette, a series of questions pertaining to the vignettes were presented. After completion of all five vignettes, participants received additional measures (described later).

c. Participants. Participants were 124 adults from a national U.S. sample who are registered with a social science web survey distribution site based out of the University of Syracuse. Those who participated in the study were entered into a survey distribution drawing for a chance to win a $\$ 100$ gift card for online shopping. Online surveys have been shown to elicit similar results as telephone surveys; they are useful in understanding how people develop certain attitudes (Best et al. 2001), while also having quicker response rates than mailed surveys (Tse 1998). Because Internet-based samples tend to include more white middle-aged men (Hewson et al. 1996; O'Neil \& Penrod 2001) and caregivers tend more often to be white middle-aged women (Brody 1990), we oversampled women in our 
recruitment to ensure a representative sample of potential caregivers. The total sample consisted of 39 percent male and 61 percent female. Participant age ranged from 20 to 69 years old $(M=47, S D=11.3)$. The majority of participants were white $(70.4$ percent $)$, followed by Asian (12.6 percent), black (3 percent), Hispanic (3 percent), and other/multiracial (1.4 percent).

Our sample originally included 177 respondents, but we excluded participants if the time they spent on the study was less than eight minutes $(n=43)$ or more than 60 minutes $(n=9)$. Pilot testing of the instrument revealed that spending less than eight minutes most likely represented a person clicking through the study without reading the questions. Spending more than 60 minutes likely represented participants who left the study while in progress and therefore we could not confirm they were still sensitive to the study manipulations. The final sample represents a 22 percent response rate (800 participants were solicited). This response rate is similar to other Internet-based studies, which have reported response rates of approximately 20 percent (Swoboda et al. 1997; Tse 1998).

\section{d. Measures.}

i. Vignettes. Self-referencing methodology techniques (O'Connor et al. 2004; Wiener \& Hurt 2000) were included because prior studies have shown that they do a better job eliciting empathy and credibility than vignettes that concern only fictional characters ( $\mathrm{O}^{\prime} \mathrm{Connor}$ et al. 2004). The current study asks participants to think of themselves as the potential caregiver depicted in the vignette and decide whether they would consider themselves a caregiver in the given situation. The vignettes for the current experiment have been adapted from previous research examining elder and caregiver attitudes. They describe a variety of social, physical, and cognitive problems an elder may encounter (Horowitz et al. 1991) and are manipulated to depict varying levels of assistance the elder would require in order to test whether level of need influences one's judgments about caregiving (Wolfson et al. 1993). Level of help is manipulated and reflects varying degrees of elder autonomy (Albert et al. 1996; Katz 1983). The levels included in the vignettes are: help with managing finances, major financial help, some physical help, major physical help, and both financial and physical help. The relationship between the elder in the vignette and the caregiver was manipulated across all five vignettes and was derived from the legal definitions of "caregiver" as found in the Florida statute:

a person who has been entrusted with or has assumed responsibility for the care or property of an elderly person or disabled adult and includes but not limited to, relatives, court-appointed or voluntary guardians, adult household members, neighbors, health care providers, and employees and volunteers of facilities. (Fla. Stat. $\S 825.101)$

The five relationships presented in the vignettes for the current experiment were mother/ father, spouse, aunt/uncle, client for a hired home assistant, and roommate. The description for mother/father and aunt/uncle varied according to the gender of the elderly person depicted in the vignette. The vignette depicting a parent that includes both financial and 
physical help was based on the facts of the Sieniarecki v. State of Florida (2000) case that was described earlier in this article (see Appendix B for example vignettes).

ii. Manipulation checks. After reading the vignettes, two questions were presented to ensure the participant was sensitive to the variable manipulations. The website required participants to answer both manipulation check questions correctly before the next series of questions was presented. If a participant answered incorrectly, the prompt said "incorrect, please try again" and the number of attempts was recorded into the database. For the remaining sample $(n=124)$, the majority had zero wrong attempts $(n=116)$, then one wrong attempt $(n=4)$, two wrong attempts $(n=3)$, and three wrong attempts $(n=1)$.

iii. Dependent measures: Obligation and responsibility to provide care. As dependent measures, participants were asked three questions related to providing care for the elder depicted in the vignette. One question asked participants to indicate whose overall responsibility it was to care for the elder depicted, using a six-point Likert scale ranging from 1 (elder's responsibility) to 6 (participant's responsibility) $(M=4.4, S D=1.8$ across all manipulations). In accord with prior research (Wolfson et al. 1993) and to better understand the decision behind overall responsibility to provide care, participants were also asked about their felt moral and legal obligation to provide care. Both questions asked participants to indicate how morally and legally obligated they would feel to provide the elder with the help he or she needed, using a six-point Likert scale ranging from 1 (no obligation) to 6 (total obligation $)\left(M=4.9, S D=1.5, M=3.7, S D=2.1\right.$, respectively, across all manipulations). ${ }^{1}$

iv. Filial responsibility scale. Participants were also given a scale, developed from previous research by Gans and Silverstein (2006), that measures filial responsibility. The six-item filial responsibility scale asks questions about filial responsibility attitudes toward an elderly parent, such as: "Regardless of the sacrifices involved, how much responsibility should adult children with families of their own have to provide companionship or spend time with elderly parents who are in need?" Response options were on a five-point Likert scale that ranged from 0 (no responsibility) to 5 (total responsibility). Total scores were averaged across all items to create a total average filial responsibility score, with higher scores representing higher levels of filial responsibility. The majority of participants reported moderately high levels of filial responsibility $(M=3.3, S D=0.75$; Cronbach's $\alpha=0.89)$. Females had similar filial responsibility attitudes to males $(M=3.3, S D=0.13 ; M=3.2, S D=0.11$, respectively). Whites had similar filial responsibility attitudes to nonwhites $(M=3.2, S D=$ $0.08 ; M=3.3, S D=0.08$, respectively).

\section{Results}

a. Analytic Strategy. To better understand participants' caregiving notions, we used SAS PROC MIXED to conduct multilevel regression analyses (Littell et al. 1996) accounting for vignette variance and participant variance. Experiments that manipulate vignettes produce data from two levels for analyses: the vignette level and the individual level. Because data are collected from participants over multiple vignettes, mixed-model ANOVAs would 
not be appropriate. In data such as these, where the design is within subjects, but participants do not receive all vignette conditions (i.e., participants received 5 of 25 vignettes), crossed-effects models are usually used to account for both participant and vignette fixed effects (for an overview, see Locker et al. 2007). However, for this study, once the vignette interaction term is included in the vignette-only model (as explained below), the random effects for vignette are no longer needed because the interaction term (RELATION $\times$ HELP) explains all the variance. Therefore, the models for the following analyses are all two-level multilevel models, which include the vignette interaction term to account for item random effects. Assumptions for regression and multilevel analysis have been met.

b. Overall Responsibility to Provide Elder Care. Our first goal in Study 2 was to examine whether participants viewed either themselves or the elder as having the most overall responsibility to provide care, based on two manipulated vignette variables: the relationship between the elder and potential caregiver, and the level of help needed by the elder. It was hypothesized that participants would most likely view themselves as a caregiver in the condition depicting a "typical" caregiving scenario, based on the opinion in the Sieniarecki (2000) case, where an adult child was living with a parent needing both physical and financial help. Other relationships (e.g., a roommate) and less help needed (e.g., only financialmanagement help needed) would be less likely to produce strong caregiving notions in the participants.

For the overall responsibility dependent measure, we examined two regression equations. The first examined the effects of the vignette-only variables, while still accounting for participant-level variance. In this model, relationship of the elder (RELATION) and the level of help needed (help), as well as their interaction (RELATION $\times$ HELP), were included as predictors. The second regression equation examined the effects of the vignette variables and participant-level variables as predictors (GENDER, RACE, AGE (centered at age 50), all higher-order interactions of these demographics, and FILIAL RESPONSIBILITY) to examine specific participant characteristics that may contribute to overall caregiving responsibility notions, while still accounting for both levels of variance. In this second regression analysis, the vignette-level variables remained significant predictors, even while controlling for these participant-level variables. SAS PROC MIXED does not provide an overall $F$ statistic for the model; therefore, a proportion reduction estimate between the two models must be calculated. The calculated proportion reduction estimate was $R^{2}=0.30$, which means the model containing participant-level variables does explain additional variance for felt overall responsibility compared to the vignette-level-only model (Raudenbush \& Bryk 2002). Thus, results from this second regression analysis that include participant variables will be the model used.

In this model, significant main effects differences were found for the relationship variable $\left(F(4,480)=75.23, p<0.001, \eta^{2}=0.38\right)$, where relationship was treated as a dummy variable with parent as the comparison category. Regression weights demonstrate that a spouse $(B=0.30, S E=0.44, p=0.49)$ is the only relationship not significantly different from a parent. Those relationships that are different from a parent showed that participants have lower overall responsibility for a relative $(B=-1.47, S E=0.38, p<0.001)$, roommate $(B=-2.81$, $S E=0.39, p<0.001)$, and a client $(B=-0.66, S E=0.40, p=0.09)$. The second vignette-level 
variable, level of help needed, was also treated as a dummy variable and the comparison category was the vignette that included both physical and financial help needed. For this predictor, significant main effects differences were found $\left(F(4,480)=8.69, p<0.001, \eta^{2}=0.07\right)$. Results reveal that major financial help was the only group that was different than the comparison $(B=-0.88, S E=0.39, p=0.02)$, and that all other levels were similar to both physical and financial help. Results from the interaction model revealed the interaction was also significant $\left(F(16,369)=2.84, p<0.001, \eta^{2}=0.11\right)$; however, the only regression weights that were different from the comparison group were a roommate requiring major financial help $(B=1.52, S E=0.59, p=0.01)$ and a roommate requiring some physical help $(B=0.99, S E=0.58, p=0.08)$.

With respect to participant variables, filial responsibility attitudes were measured using Gans and Silverstien's scale (FILIAL RESPONSIBILITY) and this was the only participant-level variable that significantly contributed to the model $(B=0.53, S E=0.11, p<0.001)$. Specifically, those having higher scores on the filial responsibility scale are more likely to perceive themselves as the caregiver in the vignette situations (see Table 2).

Table 2. Full Model Multilevel Regression Predicting Overall Responsibility to Provide Elder Care Using Vignette and Participant Level

\begin{tabular}{lccc}
\hline Predictor Variables & Estimate & SE & $\mathrm{t}$ \\
\hline Relation (dummy coded, parent $=0$ ) & & & \\
Spouse & 0.30 & 0.44 & 0.68 \\
Aunt/uncle & -1.47 & 0.38 & $-3.87^{* *}$ \\
Roommate & -2.81 & 0.39 & $-7.21^{* *}$ \\
Client & -0.66 & 0.40 & $-1.65^{*}$ \\
Help needed (dummy coded, both financial and physical $=0$ ) & & \\
Financial management & 0.12 & 0.40 & 0.29 \\
Major financial & -0.88 & 0.39 & $-2.27^{*}$ \\
Some physical & -0.01 & 0.38 & -0.02 \\
Major physical & -0.17 & 0.44 & -0.39 \\
Participant level & & & \\
Race (dummy coded, $0=$ nonwhite) & & & \\
Gender (dummy coded, $0=$ male) & 0.71 & 0.30 & $2.39^{*}$ \\
Age & -0.06 & 0.19 & -0.33 \\
Race $\times$ Gender & 0.01 & 0.02 & 0.63 \\
Race $\times$ Age & -0.74 & 0.4 & -1.86 \\
Gender $\times$ Age & -0.01 & 0.03 & -0.34 \\
Race $\times$ Gender $\times$ Age & -0.02 & 0.03 & -0.53 \\
Filial responsibility & 0.03 & 0.04 & 0.81 \\
\hline
\end{tabular}

${ }^{* *} p<0.001 ;{ }^{*} p<0.05$, two-tailed significance test

Note: Positive values indicate higher felt overall responsibility compared to variable dummy coded as 0 . $N=620$ vignette responses, $n=124$ participants.

c. Felt Moral and Legal Responsibility to Provide Elder Care. The second goal of Study 2 was to explore how participants perceived moral and legal obligations to provide care 
based on the two manipulated vignette variables: relationship and level of help needed. Similar to the analysis for overall responsibility, the first regression analysis for moral obligation contained the vignette-level variables. In this model, RELATION $(F(4,480)=64.48$, $\left.p<0.001, \eta^{2}=0.35\right)$ and HELP NEEDED $\times$ RELATION $\left(F(16,360)=2.20, p=0.005, \eta^{2}=0.08\right)$ were significant predictors; however, HELP NEEDED was not $\left(F(4,480)=1.72, p=0.14, \eta^{2}=0.02\right)$. The regression weight values for moral obligation showed that the only relationship not different from a parent was a spouse $(B=0.08, S E=0.40, p=0.85)$. With respect to the other relationship predictors, participants had a lower felt moral obligation compared to a parent for a relative $(B=-0.9, S E=0.34, p=0.008)$, client $(B=-1.26, S E=0.36, p<0.001)$, then roommate $(B=-2.32, S E=0.35, p<0.001)$. There were no significant differences compared to both financial and physical help (the comparison predictor) across level of help for moral obligation, so these values will not be discussed (see Table 3). The same participant-level variables were then included in a second regression analysis (GENDER, RACE, AGE (centered at age 50), all higher-order interactions, and FILIAL RESPONSIBILITY). To calculate the proportion of variability in the data that is accounted for in the model containing the additional participant-level predictors, the proportion reduction estimate was $R^{2}=0.02$, which means the model containing participant-level variables does not explain much more of the variance for moral obligation then the vignette-level model (Raudenbush \& Bryk 2002). Therefore, results from this second moral obligation regression examining participantlevel variables are not discussed.

Table 3. Separate Regression Analyses Predicting Moral and Legal Obligation to Provide Elder Care Using Vignette Level and Accounting for Participant-Level Variance

\begin{tabular}{|c|c|c|c|c|c|c|}
\hline \multirow[b]{2}{*}{ Predictor Variables } & \multicolumn{3}{|c|}{ Moral } & \multicolumn{3}{|c|}{ Legal } \\
\hline & Estimate & SE & $\mathrm{t}$ & Estimate & SE & $\mathrm{t}$ \\
\hline \multicolumn{7}{|c|}{ Relation (dummy coded, parent $=0$ ) } \\
\hline Spouse & 0.08 & 0.4 & 0.19 & 1.27 & 0.51 & $2.51^{*}$ \\
\hline Relative & -0.91 & 0.34 & $-2.67^{*}$ & -1.35 & 0.44 & $-3.1^{*}$ \\
\hline Roommate & -2.32 & 0.34 & $-6.7^{* *}$ & -2.57 & 0.44 & $-5.8^{* *}$ \\
\hline Client & -1.26 & 0.36 & $-3.48^{* *}$ & 0.07 & 0.46 & 0.15 \\
\hline \multicolumn{7}{|c|}{ Help needed (dummy coded, both financial and physical $=0$ ) } \\
\hline Financial management & -0.6 & 0.36 & -1.67 & -0.62 & 0.46 & -1.35 \\
\hline Major financial & -0.29 & 0.34 & -0.83 & -0.69 & 0.44 & -1.54 \\
\hline Some physical & -0.01 & 0.34 & -0.04 & -0.28 & 0.44 & -0.64 \\
\hline Major physical & -0.33 & 0.4 & -0.84 & -0.08 & 0.51 & -0.16 \\
\hline
\end{tabular}

${ }^{* *} p<0.001 ;{ }^{*} p<0.05$, two-tailed significance test.

Note: Positive values indicate higher felt moral and legal responsibility compared to variable dummy coded as 0 . $N=620$ vignette responses, $n=124$ participants.

For legal obligation, the vignette-level predictors RELATION $(F(4,480)=104.53, p<0.001$, $\left.\eta^{2}=0.46\right)$, HELP NEEDED $\left(F(4,480)=2.82, p=0.03, \eta^{2}=0.02\right)$, and HELP NEEDED $\times$ RELATION $\left(F(16,373)=2.27, p=0.004, \eta^{2}=0.08\right)$ were significant predictors in the model. For legal obligation, the only predictor not different from the parent comparison was a client hired to help $(B=0.07, S E=0.46, p=0.88)$. Other relationships showed differences from a 
parent-participants felt more legal obligation for a spouse $(B=1.27, S E=0.51, p=0.01)$, and less legal obligation for a relative $(B=-1.34, S E=0.44, p=0.002)$ or roommate $(B=-2.57$, $S E=0.44, p<0.001)$. There were no significant differences compared to both financial and physical help (the comparison predictor) across level of help for legal obligation, so these values will not be discussed (see Table 3). Similar to the previous analyses, the same participant-level variables were then included into a second regression analysis (GENDER, RACE, AGE (centered at age 50), FILIAL RESPONSIBILITY, and higher-order interactions) for legal obligation. To calculate the proportion of variability in the data that is accounted for in the model containing the additional participant-level predictors, the proportion reduction estimate was $R^{2}=0.03$, which means the model containing participant-level variables does not explain much more of the variance for moral obligation then the vignette-level model (Raudenbush \& Bryk 2002). Therefore, results from this second legal obligation regression examining participant level are not discussed.

\section{Study 2 Discussion}

The results from our second study indicate that the threshold for when participants consider themselves responsible for the elder varies across participants, as well as across variations in the caregiving situation. In accordance with the opinion in the Sieniarecki (2000) case, when an adult child is living with a parent, he or she is likely to consider himself or herself the caregiver. Similarly, participants are likely to view themselves as the caregiver when the elder is their spouse. Furthermore, when the vignette described an elder who was a roommate, participants were less likely to consider themselves as responsible for providing care. This suggests that potential caregivers viewed a roommate, a person who is both a nonrelative and in a nonpaid relationship, as not their responsibility. Of course, according to some state statutory definitions (e.g., Alaska Stat. § 47.24.900; Fla. Stat. § 825.01; O.C.G.A. § 49-6-72), adult household members and even neighbors can be considered caregivers if they have "assumed" the responsibility of care. Although it may seem intuitive that participants view themselves as more responsible for the elder when the elder is more closely "related" to them, there must be some underlying factors that contribute to these differences across relationships that may influence whether a person perceives himself or herself as a caregiver.

Although level of help needed appears to contribute somewhat to a person's decision and acknowledgment of the role as a caregiver, it does not appear to be as influential as the relationship component for this decision. In the current study, an elder requiring major financial help was the only level that was revealed to be different from the comparison category. The explanation for this, once again, may be due to the underlying factors that influence participants according to their relationship to the elder; more specifically, when someone decides to provide care for an elder, their felt responsibility is primarily attributable to their relationship to the person, rather than how much help is needed. Furthermore, there may also be underlying factors that contribute to a potential caregiver's felt responsibility to care for an elder who requires major financial help. Some potential caregivers may not feel they are financially able to provide for the elder this way. Moreover, potential caregivers may also feel that an elder requiring major financial help should receive assistance from other sources, such as the government. 
Most state statutes recognize that once a person "assumes responsibility" to provide elder care, it is illegal to ignore an elder's basic needs, regardless of a caregiver's relation to the elder or how much care the elder needs. Unlike state statutes that view caregiver responsibilities as universal across these two variables, results from this study demonstrate that potential caregivers view their level of obligation differently with respect to relationship and to the elder and how much help is needed. To reduce unintentional neglect, therefore, it may be pertinent to bring these issues to potential caregivers' awareness, while also reducing the fear caregivers may have of legal ramifications. Moreover, because participants had higher felt moral obligations than legal obligations, rather than focus on the legal consequences of abuse statutes, policy should focus on strengthening social norms of providing care and educating caregivers about how to navigate the dichotomy between elder autonomy and paternalistic caregiving (Caputo 2002).

\section{General Discussion}

Both current studies examine the legal standards for elder caregiving. They are a first attempt to experimentally examine some of the assumptions the law makes about such care and examine in depth how families make these decisions. Based on the findings from the experimental study, the participants in our sample had inconsistent levels of felt responsibility toward the described elders. Especially important is the differential level of responsibility dependent on the described relationship because the law makes no concession for different relationships in determining a caregiver relationship.

Moral obligations were a motivating force for the participants in the experimental study and for the actual interviewed caregivers. The results from these studies demonstrate that individuals may become caregivers due to what feels like a moral decision, yet once caregivers have "assumed responsibility" to provide care, they may have taken on a legal obligation. In addition, the decision to take on caregiving is often made quickly at a specific health event and with the intention for it to be a short-term solution, but the caregiving evolves into a permanent living arrangement for which caregivers are not well prepared for the emotional or physical commitment of providing care. The gradual degeneration that people go through when they age exacerbates the complications of caregiving and a caregiver's knowledge of when official caregiving begins.

Many caregivers provide care for an elder because of individual values such as respect for the elder (Dellmann-Jenkins \& Brittain 2003; Ohuche \& Littrell 1989) or felt moral obligations (Bracci 2000; Wolfson et al. 1993). Thus, an important area for future investigation will be the moral psychology perspective of caregiving. Research on morality has historically focused on moral reasoning; however, current research has begun to examine moral decisions influenced by emotional reactions, termed moral emotions (Haidt 2003). Moral emotions are defined as those emotions that either respond to moral violations or motivate moral behavior and include both negative and positive emotions, such as shame, guilt, gratitude, and pride (Haidt 2003; Tangney et al. 2007). Moral emotions are thought to be a key element between moral standards and moral behavior (Tangney et al. 2007) and Haidt's model of moral emotions suggests that people make decisions based on felt emotions and retrospectively justify their behavior based on a moral judgment. Applying this 
model to elder caregiving decisions implies that when potential caregivers are presented with an aging loved one requiring care, their initial decision is based on affective reactions. Subsequently, when asked about their reasons for providing care, caregivers attribute their behavior to their moral obligations. Studies exploring extrinsic or intrinsic motivations for caregiving have cited moral emotions, such as guilt, as motivators for providing elder care (Lyonette \& Yardley 2003). On this basis, one could argue that the motivation to provide elder care, or whether a person considers himself or herself to be a caregiver, may rely on affect-related decisions and judgments. For these reasons, examining the role of emotions in caregiving decisions is an important next step.

\section{A. Future Proposed Policy on Elder Neglect and Caregiving}

Scholars have begun to propose caregiving policies aimed at reducing caregiver burden and increasing informal elder care. One such proposition is to provide informal caregivers with direct financial payment or incentive for providing elder care (Kunkel et al. 2004). Empirical evidence collected within current programs that pay family caregivers suggests that payment may be beneficial because elders and caregivers in the paid caregiver group experienced more satisfaction with caregiving (Kunkel et al. 2004). Because caregiver stress is often cited as a precursor for elder abuse and neglect, increasing satisfaction through caregiver payment may be a viable solution for reducing elder abuse and neglect. Additionally, private incentive programs for providing care have been suggested. In an empirical study, Caputo (2002) tested motivational models of human behavior based on exchange and altruism theories to exemplify whether incentive programs would be effective. Specifically, this study sought to understand whether daughters acted as rational agents by choosing to care for an aging parent because of personal gain, or rational actors by choosing to care because of social norms of filial responsibility. Findings from the study demonstrate that inheritance-related factors had no bearing on providing daily care, such as help with chores, suggesting the women were motivated by social norms. On the other hand, inheritance-related factors did increase the likelihood of providing financial assistance, suggesting that issues surrounding financial affairs may be motivated by self-interest (Caputo 2002). Results suggest that caregiving policy and law should work toward strengthening normative expectations and bonds relating to filial responsibility to promote assisting with daily caregiving tasks, whereas policy aimed at increasing financial support, such as filial responsibility laws, would be most effective through financial incentives.

These suggested "fixes" will not address caregiver concerns about the legal requirements of providing care. According to Wackerbarth and Johnson (2002), the need to better understand legal issues concerning elder caregiving was ranked higher than other issues, even higher than the elder's medical diagnosis. Once people are familiar with these laws, though, they may reject providing care. The laws create a conflicting dichotomy between elder caregiving and autonomy. Medical laws prevent caregivers from implementing unwanted medical interventions to a consenting adult, yet caregiver laws require caregivers to fulfill medical treatment in the elders' best interest. Because familial informal caregiving is described as the "backbone" of contemporary long-term care in the United States (Kapp 2004), it could be detrimental to society as a whole if willingness for families to provide care decreased. 


\section{Conclusion}

Although some researchers have suggested similarities between issues that relate to children and to the elderly, others have found differences that suggest elder issues may have unique implications (Kohn 2003). For example, laws surrounding caregivers for children are less questionable because individuals under the age of 18 are declared unable to care for themselves; however, elder laws are not as standardized as in juvenile law because elder adults lose their autonomy at variable stages (if at all). Moreover, the sense of personal autonomy that has become fundamental in today's society poses unique challenges because it becomes difficult to hold individuals responsible for caring for an elder adult without interfering with the elder adult's civil rights. As the population continues to age and live longer, it is important that legal policies reflect the needs of elders and their caregivers. The current research provides an initial step toward understanding what these families need.

Acknowledgments - This research was supported by an American Psychology-Law Society Interdisciplinary Grant. For helpful comments and suggestions, we thank Nina A. Kohn, Elizabeth Peters, and participants at the 2008 Conference on Empirical Legal Studies. Thank you also to Orli Zaprir, Christopher King, Ashley Kolnes, Lesa Hoffman, and an anonymous reviewer.

\section{Note}

1. Overall responsibility and legal obligation were both normally distributed. Moral responsibility was negatively skewed and a reflected log transformation was performed. Results from the log transformation of moral obligation were similar to the nontransformed moral obligation results; thus, the nontransformed analysis will be reported.

\section{References}

Adams, D. L. (1969) “Analysis of a Life Satisfaction Index,” 24 J. of Gerontology 470

Alaska Stat. § 47.24 .900 (2009) Title 47, Chapter 24. Protection of Vulnerable Adults.

Albert, S. M., M. Moss, \& M. P. Lawton (1996) “The Significance of Self-Perceived Start of Caregiving," 2 J. of Clinical Geropsychology 161.

Anetzberger, G. J. (2000) “Caregiving: Primary Cause of Elder Abuse?” Summer Generations 46.

Barber, J. W. (2008) “The Kids Aren't All Right: The Failure of Child Abuse Statutes as a Model for Elder Abuse Statutes," 16 Elder Law J. 107.

Baumeister, R. F., K. D. Vohs, \& D. M. Tice (2006) “Emotional Influences on Decision-Making," in J. P. Forgas, ed., Affect in Social Thinking and Behavior, pp. 143-75. New York/Hove: Psychology Press.

Best, S. J., B. Krueger, C. Hubbard, \& A. Smith (2001) "An Assessment of the Generalizability of Internet Surveys," 19 Social Science \& Computer Rev. 131.

Bonnie, R. J., \& R. B. Wallace (2003) Elder Mistreatment: Abuse, Neglect, and Exploitation in an Aging America. National Research Council (U.S.) Panel to Review Risk and Prevalence of Elder Abuse and Neglect. Washington, DC: National Academies Press.

Bracci, C. (2000) “Ties That Bind: Ontario's Filial Responsibility Law,” 17 Canadian J. of Family Law 455. 
Brank, E. M. (2007) “Elder Research: Filling an Important Gap in Psychology and Law,” 25 Behavioral Sciences $\&$ the Law 1.

Brody, E. (1990) Women in the Middle: Their Parent Care Years. New York: Springer.

Butler, S. S., W. Turner, L. W. Kaye, L. Ruffin, \& R. Downey (2005) “Depression and Caregiver Burden among Rural Elder Caregivers," 46(1) J. of Gerontological Social Work 47.

Caputo, R. K. (2002) “Adult Daughters as Parental Caregivers: Rational Actors Versus Rational Agents," 23 J. of Family \& Economic Issues 27.

Cicirelli, V. G. (1990) "Relationship of Personal-Social Variables to Belief in Paternalism in Parent Caregiving Situations," 5(3) Psychology \& Aging 458.

_ (2000) "An Examination of the Trajectory of the Adult Child's Caregiving for an Elder Parent," 49 Family Relations 169.

_. (2003) "Mother's and Daughter's Paternalism Beliefs and Caregiving Decision Making," 25 Research on Aging 3.

Connecticut Conn. Gen. Stat. §46b-215 (2008) Title 46b, Chapter 816. Relatives Obliged to Furnish Support.

Delaware 31 § 3902 (2008). Title 31, Part II, Chapter 39. Adult Protective Services, Definitions.

Dellmann-Jenkins, M., \& L. Brittain (2003) “Young Adults' Attitudes towards Filial Responsibility and Actual Assistance to Elderly Family Members," 22 J. of Applied Gerontology 214.

Edelstone, S. F. (2002) "Filial Responsibility: Can the Legal Duty to Support Our Parents Be Effectively Enforced?" 36 Family Law Q. 501.

Fla. Stat. § 415.102 (2008). Title 30, Chapter 416. Adult Protective Services, Definitions.

Fla. Stat. § 825.101 (2008). Title 46, Chapter 825. Abuse, Neglect, and Exploitation of Elderly Persons and Disabled Adults.

Fondacaro, M. R., S. L. Jackson, \& J. Luescher (2002) “Toward the Assessment of Procedural and Distributive Justice in Resolving Family Disputes," 15 Social Justice Research 341.

Ford, A. B., M. R. Haug, K. C. Stange, A. D. Gaines, L. S. Noelker, \& P. K. Jones (2000) "Sustained Personal Autonomy: A Measure of Successful Aging," 12 J. of Aging $\mathcal{E}$ Health 470.

Gans, D., \& M. Silverstein (2006) “Norms of Filial Responsibility for Aging Parents Across Time and Generations," 68(4) J. of Marriage \& Family 961.

Georgia O.C.G.A. § 49-6-72 (2008). Title 49, Chapter 6, Article 6. Georgia Family Caregiver Support, Definitions.

Glick, J. B. (2005) “Protecting and Respecting Our Elders: Revising Mandatory Elder Abuse Reporting Statutes to Increase Efficacy and Preserve Autonomy," 12 Virginia J. of Law \& Policy 714.

Haidt, J. (2003) “The Moral Emotions," in R. J. Davidson, K. R. Scherer, \& H. H. Goldsmith, eds., Handbook of Affective Sciences, pp. 852-70. Oxford: Oxford Univ. Press.

Health and Human Services and Assistant Secretary for Planning and Evaluation (2003) The Future Supply of Long-Term Care Workers in Relation to the Aging Baby Boom Generation. Report to Congress. Washington, DC: Health and Human Services.

Heron, M. P., D. L. Hoyert, J. Xu, C. Scott, \& B. Tejada-Vera (2008). “Deaths: Preliminary Data for 2006," 56(16) National Vital Statistics Reports.

Hewson, C. M., D. Laurent, \& C. M. Vogel (1996) "Proper Methodologies for Psychological and Sociological Studies Conducted via the Internet," 28 Behavior Research Methods, Instruments, \& Computer 186.

Horowitz, A., B. M. Silverstone, \& J. P. Reinhardt (1991) “A Conceptual and Empirical Exploration of Personal Autonomy Issues within Family Caregiving Relationships," 31 Gerontologist 23. 
Illinois § 320 ILCS 20/2 (2009). Chapter 320. Aging Elder Abuse and Neglect Act.

Illinois $\S 720$ ILCS 5/12-21 (2009). Chapter 720. Criminal Abuse or Neglect of an Elderly Person or Person with a Disability.

Indiana § 35-46-1 (2008). Title 35, Article 46, Chapter 1. Offenses Against Family.

Jayawardena, K. M., \& S. Liao (2006) “Elder Abuse at End of Life," 9(1) J. of Palliative Medicine 127.

Kapp, M. B. (1995) “Elder Mistreatment: Legal Interventions and Policy Uncertainties," 13(3) Behavioral Sciences \& the Law 365.

—. (2004) "Family Caregivers' Legal Concerns," 27(4) Generations 49.

Katz, S. (1983) "Assessing Self-Maintenance: Activities of Daily Living, Mobility, and Instrumental Activities of Daily Living," 12 J. of American Geriatrics Society 721.

Kinney, J. M., \& M. A. P. Stephens (1989) “Caregiving Hassles Scale: Assessing the Daily Hassles of Caring for a Family Member with Dementia," 29 Gerontological Society of America 328.

Kohn, N. (2003) "Second Childhood: What Child Protection Systems Can Teach Elder Protection Systems," 14 Stanford Law \& Policy Rev. 175.

Kunkel, S. R., R. A. Applebaum, \& I. M. Nelson (2004) “For Love and Money: Paying Family Caregivers," 27(4) Generations 74.

Lee, G. R., R. T. Coward, \& J. K. Netzer (1994) “Residential Differences in Filial Responsibility Expectations among Older Persons," 59 Rural Sociology 100.

Littell, R. C., G. A. Milliken, W. W. Stroup, \& R. D. Woltinger (1996) SAS System for Mixed Models. Cary, NC: SAS Institute, Inc.

Locker, L., L. Hoffman, \& J. A. Bovaird (2007) “On the Use of Multilevel Modeling as an Alternative to Items Analysis in Psycholinguistic Research," 39 Behavioral Research Methods 723.

Louisiana R.S. 14:93.3 (2008). Title 14, Chapter 1, Part 5B3. Offenses Affecting the Health and Safety of the Infirm.

Lyonette, C., \& L. Yardley (2003) “The Influence on Carer Well-being of Motivations to Care for Older People and the Relationship with the Care Recipient," 23(4) Ageing \& Society 487.

Massachusetts ALM ch. $273 \S 20$ (2008) Chapter 273. Desertion, Non-Support, and Illegitimacy.

Moskowitz, S. (2001) "Filial Responsibility Statutes: Legal and Policy Considerations," 3 J. of Law \& Policy 709.

Neugarten, B. L., R. J. Havighurst, \& S. S. Tobin (1961) “The Measurement of Life Satisfaction,” 16 J. of Gerontology 134.

New Hampshire RSA 167:3 (2008). Chapter 167. Public Assistance to Blind, Aged, or Disabled Persons, and to Dependent Children, Compelling Support.

O'Connor, M., B. A. Gutek, M. Stockdale, T. M. Geer, \& R. Melancon (2004) “Explaining Sexual Harassment Judgments: Looking beyond Gender and Rater," 28 Law \& Human Behavior 69.

Ohuche, N. M., \& J. M. Littrell (1989) "Igbo Students' Attitudes toward Supporting Aged Parents," 29 International J. of Aging \& Human Development 259.

O'Mara, A. (2005) “Who's Taking Care of the Caregiver?" 23(28) J. of Clinical Oncology 6820.

O’Neil, K. M., \& S. D. Penrod (2001) “Methodological Variables in Web-Based Research that May Affect Results: Sample Type, Monetary Incentives, and Personal Information," 33 Behavior Research Methods, Instruments, \& Computers 226.

Pakula, M. (2005a) “A Federal Filial Responsibility Statute: A Uniform Tool to Help Combat the Wave of Indigent Elderly," 39 Family Law Q. 859. 
. (2005b) "The Legal Responsibility of Adult Children to Care for Indigent Parents," $521 \mathrm{Na}$ tional Center of Policy Analysis Brief Analysis 1.

Raudenbush, S. W., \& A. S. Bryk (2002) Hierarchical Linear Models: Applications and Data Analysis Methods. Thousand Oaks, CA: Sage Publications.

Reis, H. T., K. M. Sheldon, S. L. Gable, J. Roscoe, \& R. M. Ryan (2000) “Daily Well-Being: The Role of Autonomy, Competence, and Relatedness," 26 Personality \& Social Psychology Bulletin 419.

Rosenbaum, M. (1967) “Are Family Responsibility Laws Constitutional?” 55 Family Law Q. 76.

Sieniarecki v. Florida, 756 So. 2 d 68 (2000).

South Carolina Code Ann. $\S 43-35-10$ (2007). Title 43, Chapter 35, Article 1. Duties and Procedures of Investigative Entities.

South Dakota Codified Laws § 25-7-27 (2009). Title 25, Chapter 25-27. Support Obligations, Duty of a Child to Provide for a Necessaries Parent.

Stull, D. E., K. Kosloski, \& K. Kercher (1994) “Caregiver Burden and Generic Well-Being: Opposite Sides of the Same Coin?" 34 Gerontological Society of America 88.

Swoboda, W. J., N. Muhlberger, R. Weitkunat, \& S. Schneeweiss (1997) “Internet Surveys by Direct Mailing: An Innovative Way of Collecting Data," 15 Social Science Computer Rev. 242.

Tangney, J. P., J. Stuewig, \& D. J. Mashek (2007) "Moral Emotions and Moral Behavior," 58 Annual Rev. of Psychology 345.

Teaster, P. B., T. A. Dugar, M. S. Mendiondo, E. L. Abner, \& K. A. Cecil (2006) The 2004 Survey of State Adult Protective Services: Abuse of Adults 60 Years of Age and Older. National Center on Elder Abuse. Available at http://www.nasua.org

Tse, A. C. B. (1998) “Comparing the Response Rate, Response Speed and Response Quality of Two Methods of Sending Questionnaires: E-Mail vs. Mail," 40 J. of the Market Research Society 353.

van der Pas, S., T. van Tilburg, \& K. P. M. Knipscheer (2005) "Measuring Older Adults' Filial Responsibility Expectations: Exploring the Application of a Vignette Technique and an Item Scale," 65(6) Educational \& Psychological Measurement 1026.

Wackerbarth, S. B., \& M. M. S. Johnson (2002) “Essential Information and Support Needs of Family Caregivers," 47 Patient Education \& Counseling 95.

Wallace, K. A., \& A. J. Wheeler (2002) "Reliability Generalization of the Life Satisfaction Index," 62 Education \& Psychological Measurement 674.

Wiener, R. L., \& L. E. Hurt (2000) “How Do People Evaluate Social Sexual Conduct at Work? A Psycholegal Model," 85 J. of Applied Psychology 75.

Wolfson, C., R. Handfield-Jones, K. C. Glass, J. McClaran, \& E. Keyserlingk (1993) “Adult Children's Perceptions of Their Responsibility to Provide Care for Dependent Elderly Parents," 33 Gerontologist 315. 


\section{Appendix A}

Study 1 open-ended decision to live together questions for nonelders (elder questions were complementarily worded).

Next, we're going to talk in some more detail about the decision-making process that you went through when \{insert elder's name here \} came to live with you/you came to live with him/her. We want to find out how that decision was made and who was involved in that decision.

1. Was there some sort of an event or life change that occurred resulting in the current living situation?

2. Was the living arrangement intended to be long-term? In other words, were there any discussions and what were they like, about your current living arrangements with \{insert elder's name here \}.

3. Who did you talk to about the decision to move \{insert elder's name here $\}$ in with you? What were the other options for living arrangements? Why was this one chosen? Did you consider an assisted living or nursing home facility?

4. Asked when applicable: Did you make any changes to your home after the move?

5. Do you attend doctor appointments with \{insert elder's name here \}?

\section{Appendix B}

\section{Study 1 Vignette Examples}

\section{Major Financial Help}

Alice, [insert relationship], is a 76-year-old woman who lives in a small condo. She is frail and has some minor medical problems, but she is still able to care for herself physically. Your [insert relationship] has little money because she only receives her social security monthly payments and her modest monthly check barely covers her living expenses. She can no longer pay her mortgage, her utilities are in jeopardy of being turned off, and she has several prescription medications which are very costly. Now, imagine Alice is [insert relationship], you live together, and she needs major financial help.

Some Physical Help

$\mathrm{Al}$, [insert relationship], is a 77-year-old diabetic man who had a below-the-knee amputation of the right leg 6 months ago. Since the surgery, your [insert relationship] has not been successful in learning to use his prosthetic leg, but he manages to do some things for himself. For example, $\mathrm{Al}$ can dress himself, use the restroom, administer his insulin, and he is financially self-sufficient, however, he needs help with things like cooking and cleaning. 
Now, imagine $\mathrm{Al}$ is your [insert relationship], you live together, and he needs some physical help.

\section{Major Physical Help}

John, [insert relationship], is a 79-year-old man who had a major stroke causing paralysis in his right side. Because of this weakness, he is unable to get out of bed, into his wheelchair, or onto the toilet without physical assistance. He also has a heart condition that requires daily medication to prevent a heart attack. [Insert relationship], John, requires help with all of his daily living needs. For example, someone needs to make sure John eats, bathes regularly, and takes his medication. John receives money from a military pension that pays his bills; therefore, he does not need help with his finances. Now, imagine you are [insert relationship], you live together, and he needs major physical help.

\section{Financial Management Help}

Joy, [insert relationship], is a 75-year-old woman who has been handling all of her own financial affairs herself. Even though Joy has no physical ailments, about 1 year ago Joy started displaying signs of memory loss and now has difficulty remembering to pay her bills. Now, imagine that Joy is your [insert relationship], you live together, and she needs financial management help.

\section{Both Financial and Physical Help}

Rose, [insert relationship], is a 78-year-old woman who underwent two hip surgeries. Shortly after the surgeries, her behavior became despondent and disoriented. She appears to have given up and even though it appears she can walk, she will not walk at all. She was forced to sell her home and move into an apartment because she could no longer afford her home. Since Rose will not walk, even to the bathroom, she requires adult diapers. Also, she eats very little and does not want to go to the doctor when she is suggested to go. Now, imagine you are Rose's [insert relationship], you live together, and she needs both physical and financial help. 